\title{
Application of Fuzzy Ranking Method to Determine the Replacement Time for Fuzzy Replacement Problem
}

\author{
Pranab Biswas \\ Assistant Teacher \\ Sardanga High School, \\ P.O. - Chakdaha, Nadia, \\ West Bengal, India.
}

\author{
Surapati Pramanik \\ Assistant Professor \\ Nandalal Ghosh B.T. College, Panpur, \\ P.O. - Narayanpur, North 24 Parganas \\ West Bengal, India.
}

\begin{abstract}
In every field of our real life situations, we deal with a replacement problem, when some items such as machines, medical equipment, military tank, electric bulb etc. or workers need to replace due to their decreased efficiency, failure or break down. To get a more realistic view of a replacement problem, here, we consider that the capital cost $(\tilde{\mathrm{C}})$, scrap value or resale value $(\tilde{S})$, maintenance cost or running cost $\left(\tilde{f}_{t}\right)$ are all of fuzzy numbers. These fuzzy numbers are considered as a trapezoidal fuzzy numbers or triangular fuzzy numbers. Yager's Ranking method (1981) has been used to determine the best alternative of fuzzy numbers. It has been also used to transform a replacement model with fuzzy cost to a replacement model with crisp cost. Then we solved it by any conventional method. Two numerical examples have been solved to show the effectiveness of the proposed method.
\end{abstract}

\section{General Terms}

Fuzzy Replacement Problem.

\section{Keywords}

Fuzzy set, Trapezoidal fuzzy number, Triangular fuzzy number, Fuzzy Replacement Problem, Fuzzy ranking.

\section{INTRODUCTION}

Replacement Problem (RP) is one of the practical areas in economic decision analysis for our real world system. It is used in engineering economics to determine an optimal decision for maintenance and replacement purposes. When an equipment or item is used for a long time, this item tends to worsen. Then, the need for replacement becomes necessary due to a loss of efficiency. Operating equipment for a long time, the cost of operation and the maintenance cost are bound to increase year by year. A stage will come, when the maintenance cost becomes significantly large. Therefore, it is more economical to replace the equipment with new one. Many researchers have developed different RP with different criterion. Several RP models are available in the literature. Bellman [1,2] developed at first the replacement problem as a dynamic programming (DP). He formulated a discounted DP version of the economic life of equipment and determined analytically the optimal age to replace the equipment. Wagner [3] formulated a replacement problem as a network and solved for the shortest path that corresponds to the minimum outlay. Oak ford et al [4] generalized the Wagner's dynamic programming model that allows for multiple challengers and time varying parameters. Alchian [5] studied a replacement problem where operating cost is a linear function of time. Dreyfus [6] discussed RP by considering operating cost and replacement costs as exponentially bounded.

In order to introduce a more realistic view, Dreyfus and law [6] studied RP where decision can be made stochastically. Lohmann [7] again generalized Wagner's dynamic model in stochastic concept. Recently, a fuzzy set theoretic approach is used when the assumption of a probabilistic approach are not met. It occurs when these variables are based on the estimates provided by expert using linguistic variables. Using fuzzy sets, these variables can represent the impreciseness. To solve the fuzzy replacement problem (FRP), Dong [8] proposed a method to bypass the problem involving interval and fuzzy arithmetic. Chiu and Park [9] used triangular fuzzy number (TFN) in cash flow analysis. Hearnes [10] formulated fuzzy versions of the economic life of an asset model and the finite single asset replacement problem.

In this paper, we study a realistic view that capital cost $(\tilde{\mathrm{C}})$, scrap value $(\tilde{\mathrm{S}})$, maintenance or running cost $\left(\tilde{\mathrm{f}}_{\mathrm{t}}\right)$ of equipment are all of trapezoidal fuzzy numbers (TrFNs) or triangular fuzzy numbers (TFNs). Here, we also consider the replacement of equipment or items that deteriorate with time and the value of money does not change with time. The comparison of minimum average costs is done based on average cost. It is obtained when the total cost of the capital in owning the item and its operation cost is accumulated for $\mathrm{n}$ years and this total is divided by $\mathrm{n}$. Here, our objective is to seek for the minimum average fuzzy cost, which cannot be obtained directly. Therefore, we need a ranking method to find out the best alternative. To deal with this situation, we use Yager's ranking method [11] known as robust ranking method. It satisfies compensation, linearity, and additive properties.Yager's ranking method has been used to transform the fuzzy replacement problem to crisp version so that any conventional method can be applied to solve the problem. Finally, we consider only the discrete values for the cost of various times (year, hour, etc).

\section{PRELIMINARIES OF FUZZY SETS}

Lotfi A Zadeh (1965) first introduced Fuzzy set as a mathematical way for representing impreciseness. 
2.1 Definition: Fuzzy set: A fuzzy set $\tilde{\mathrm{A}}$ in a universe of discourse $\mathrm{X}$ is defined by $\tilde{\mathrm{A}}=\left\{\left\langle\mathrm{x}, \mu_{\tilde{\mathrm{A}}}(\mathrm{x})\right\rangle \mid \mathrm{x} \in \mathrm{X}\right\}$, where $\mu_{\tilde{\mathrm{A}}}(\mathrm{x}): \mathrm{X} \rightarrow[0,1]$ is called the membership function of $\tilde{\mathrm{A}}$ and $\mu_{\tilde{\mathrm{A}}}(\mathrm{x})$ is the degree of membership to which $\mathrm{x} \in \tilde{\mathrm{A}}$.

2.2 Definition: A fuzzy set $\tilde{A}$ on $R$ is convex iff for any $x_{1}$, $\mathrm{x}_{2} \in \mathrm{X}$, the membership function of $\tilde{\mathrm{A}}$ satisfies the inequality $\mu_{\tilde{\mathrm{A}}}\left\{\lambda \mathrm{x}_{1}+(1-\lambda) \mathrm{x}_{2}\right\} \geq \min \left\{\mu_{\tilde{\mathrm{A}}}\left(\mathrm{x}_{1}\right), \mu_{\tilde{\mathrm{A}}}\left(\mathrm{x}_{2}\right)\right\}$;

$0 \leq \lambda \leq 1$. where min denotes the minimum operator

2.3 Definition: Normal Fuzzy Set: A fuzzy set $\tilde{A}$ of the universe of discourse $\mathrm{X}$ is called a normal fuzzy set implying that there exists at least one $x$ in $X$ such that $\mu_{\tilde{A}}(x)=1$.

2.4 Definition: Trapezoidal fuzzy number: A trapezoidal fuzzy number $\tilde{a}$ is denoted by $\left(a_{1}, a_{2}, a_{3}, a_{4}\right)$ where $a_{1}, a_{2}, a_{3}, a_{4}$ are real numbers and its membership function $\mu_{\tilde{\mathrm{a}}}(\mathrm{x})$ is given by:

$\mu_{\sim}(x)= \begin{cases}0, & x \leq a_{1}, \\ \frac{x-a_{1}}{a_{2}-a_{1}}, & a_{2} \leq x \leq a_{1}, \\ 1, & a_{2} \leq x \leq a_{3}, \\ \frac{a_{4}-x}{a_{4}-a_{3}}, & a_{3} \leq x \leq a_{4}, \\ 0, & x \geq a_{4}\end{cases}$

$\mu_{a}$ (x) satisfies the following conditions.

1. $\mu_{\mathrm{a}}(\mathrm{x})$ is a continuous mapping from $\mathrm{R}$ to closed interval $[0,1]$

2. $\quad \mu_{\mathrm{a}}(\mathrm{x})=0$ for every $\mathrm{x} \in\left(-\infty, \mathrm{a}_{1}\right]$

3. $\quad \mu \sim \underset{a}{ }(x)$ is strictly increasing and continuous on $\left[a_{1}, a_{2}\right]$

4. $\underset{\mathrm{a}}{\mu_{\mathrm{a}}}(\mathrm{x})=1$ for every $\mathrm{x} \in\left[\mathrm{a}_{2}, \mathrm{a}_{3}\right]$

5. $\quad \mu_{a}(x)$ is strictly decreasing and continuous on $\left[a_{3}, a_{4}\right]$

6. $\underset{\mathrm{a}}{\mu_{\mathrm{a}}}(\mathrm{x})=0$ for every $\mathrm{x} \in\left[\mathrm{a}_{4}, \infty\right)$

2.5 Definition: Triangular fuzzy number: A trapezoidal fuzzy number is denoted by $\left(a_{1}, a_{2}, a_{3}\right)$ where $a_{1}, a_{2}, a_{3}$ are real numbers and its membership function $\mu_{\tilde{a}}(\mathrm{x})$ is given below:

$\mu_{\sim}(x)=\left\{\begin{array}{lc}\frac{x-a_{1}}{a_{2}-a_{1}}, & a_{1} \leq x \leq a_{2}, \\ 1, & x=a_{2}, \\ \frac{a_{3}-x}{a_{3}-a_{2}}, & a_{2} \leq x \leq a_{3}\end{array}\right\}$
Satisfying the following conditions

1. $\mu_{a}(\mathrm{x})$ is a continuous mapping from $\mathrm{R}$ to closed interval $[0,1]$

2. $\quad \mu_{a}(x)=0$ for every $x \in\left(-\infty, a_{1}\right]$

3. $\mu_{\mathrm{a}}(\mathrm{x})$ is strictly increasing and continuous on $\left[\mathrm{a}_{1}, \mathrm{a}_{2}\right]$

4. $\underset{\mathrm{a}}{\mu_{\mathrm{a}}}(\mathrm{x})=1$ for $\mathrm{x}=\mathrm{a}_{2}$

5. $\quad \mu_{\mathrm{a}}(\mathrm{x})$ is strictly decreasing and continuous on $\left[\mathrm{a}_{3}, \mathrm{a}_{2}\right]$

6. $\mu_{\mathrm{a}}(\mathrm{x})=0$ for every $\mathrm{x} \in\left[\mathrm{a}_{3}, \infty\right)$

2.6 Definition: The $\alpha$-cut set of a fuzzy set $\tilde{\mathrm{A}}$ is a crisp set defined by $\tilde{\mathrm{A}}_{\alpha}=\left\{\mathrm{x} \in \mathrm{X} / \mu_{\tilde{\mathrm{A}}}(\mathrm{x}) \geq \alpha\right\}$.

\subsection{Arithmetic Operation:}

Fuzzy arithmetic is based on the extension principle introduced by Zadeh in 1975 [12]. The arithmetic operations of addition, subtraction, multiplication, and division developed in [13] and [14] are particularly useful when modelling and cash flow analysis.

1. Let $\tilde{\mathrm{A}}=\left(\mathrm{a}_{1}, \mathrm{a}_{2}, \mathrm{a}_{3}\right)$ and $\tilde{\mathrm{B}}=\left(\mathrm{b}_{1}, \mathrm{~b}_{2}, \mathrm{~b}_{3}\right)$ be triangular fuzzy numbers then

$$
\begin{aligned}
\tilde{\mathrm{A}}+\tilde{\mathrm{B}} & =\left(\mathrm{a}_{1}, \mathrm{a}_{2}, \mathrm{a}_{3}\right)+\left(\mathrm{b}_{1}, \mathrm{~b}_{2}, \mathrm{~b}_{3}\right) \\
& =\left(\mathrm{a}_{1}+\mathrm{b}_{1}, \mathrm{a}_{2}+\mathrm{b}_{2}, \mathrm{a}_{3}+\mathrm{b}_{3}\right)
\end{aligned}
$$

2. Similarly, let $\tilde{A}=\left(a_{1}, a_{2}, a_{3}, a_{4}\right)$ and $\tilde{B}=\left(b_{1}, b_{2}, b 3, b_{4}\right)$ be trapezoidal fuzzy numbers then

$$
\begin{aligned}
\tilde{\mathrm{A}}+\tilde{\mathrm{B}} & =\left(a_{1}, a_{2}, a_{3}, a_{4}\right)+\left(b, b_{2}, b_{3}, b_{4}\right) \\
& =\left(a_{1}+b_{1}, a_{2}+b_{2}, a_{3}+b_{3}, a_{4}+b_{4}\right)
\end{aligned}
$$

\section{FORMULATION OF REPLACEMENT MODEL}

Replacement policy can be classified into the following categories.

Case-a: When the equipment deteriorates with time and the value of money

i) does not change with time.

ii) changes with time.

Case-b: When the units fail completely all of a sudden.

In this paper, we consider the case when the value of money does not change with time.

Our purpose is to determine the optimum replacement time of an item whose running or maintenance cost increases with time and the value of money remains static during the period: 
Let C: Capital cost of equipment.

S: Scrap value of equipment.

n: number of years that equipment would be in use.

$\mathrm{f}_{\mathrm{t}}$ : maintenance cost for time $\mathrm{t}$.

A(n): Average total cost.

Here, we consider the case when, $t$ is a discrete variable. If the equipment is used for n-years, then the cost incurred during this period is given by

Total cost $=$ Capital cost - Scrap value + Maintenance cost

$\mathrm{T}(\mathrm{c})=\mathrm{C}-\mathrm{S}+\sum_{\mathrm{t}=1}^{\mathrm{n}} \mathrm{f}_{\mathrm{t}}$ and its average cost is

$\mathrm{A}(\mathrm{n})=\frac{\mathrm{C}-\mathrm{S}}{\mathrm{n}}+\frac{1}{\mathrm{n}} \sum_{\mathrm{t}=1}^{\mathrm{n}} \mathrm{f}_{\mathrm{t}}$

Here A (n) will be minimum for the value of $n$, if $A(n+1) \geq A$ (n) $\leq \mathrm{A}(\mathrm{n}-1)$.

Now, $A(n+1)=\frac{C-S}{n+1}+\frac{1}{n+1} \sum_{t=1}^{n+1} f_{t}$

$=\frac{1}{n+1}\left[C-S+\sum_{t=1}^{n} f_{t}+\frac{1}{n+1} f_{(n+1)}\right]$

$=\frac{1}{n+1}\left[\mathrm{n} \mathrm{A}(\mathrm{n})+\mathrm{f}_{(\mathrm{n}+1)}\right]$

Therefore, $A(n+1)-A(n)=\frac{1}{n+1}\left[f_{(n+1)}-A(n)\right]$

Therefore, $A(n+1) \geq A(n) \Rightarrow f_{(n+1)} \geq A(n)$.

Similarly, $A(n) \leq A(n-1) \Rightarrow f_{n} \leq A(n-1)$.

So the replacement policy can be described as flows:

Replace the equipment at the end of $n$-th year, if the maintenance cost in the $(n+1)$-th year is more than the average total cost in the nth year and the nth year maintenance cost is less than the previous year's average total cost.

Now, we investigate more realistic model of replacement problem with fuzzy capital cost $(\tilde{\mathrm{C}})$ of equipment, fuzzy scrap value ( $\tilde{S}$ ) of equipment and fuzzy maintenance cost $\left(\tilde{f}_{t}\right)$. Since the objective is to determine that time, at which the replacement is most economical instead of continuing at an increase cost. So maintenance cost is also considered as $\operatorname{TrFN}$ or TFN.

\subsection{The proposed model}

The replacement problem when the value of money does not change with time and $t$ is a discrete variable. We rewrite the average annual cost as:

$A(n)=\frac{C-S}{n}+\frac{1}{n} \sum_{t=1}^{n} f_{t}$

Now if capital cost $(\tilde{\mathrm{C}})$, scrap value $(\tilde{\mathrm{S}})$ and the maintenance $\operatorname{cost}\left(\tilde{f}_{t}\right)$ are fuzzy numbers, then the cumulative maintenance cost, total cost and average annual cost are also fuzzy numbers.

So $\tilde{\mathrm{A}}(\mathrm{n})=\frac{\tilde{\mathrm{C}}-\tilde{\mathrm{S}}}{\mathrm{n}}+\frac{1}{\mathrm{n}} \sum_{\mathrm{t}=1}^{\mathrm{n}} \tilde{\mathrm{f}}_{\mathrm{t}}$
Hence, it cannot be determined the required time directly at which the replacement is economical instead of continuing at an increased cost. For solving this problem, we first transform capital cost, scrap value, and maintenance fuzzy cost as well as its corresponding average cost into a crisp one by a Yager's ranking method. It is a robust ranking technique, which satisfies linearity and additive properties and provides result, which is consistent with human intuition. Given a convex fuzzy number $\tilde{\mathrm{C}}$, the Yager's Ranking index is defined by

$\mathrm{Y}(\tilde{\mathrm{C}})=\int_{0}^{1} 0.5\left(\mathrm{C}_{\alpha}^{\mathrm{L}}+\mathrm{C}_{\alpha}^{\mathrm{U}}\right) \mathrm{d} \alpha\left(\right.$ Where $\left(\mathrm{C}_{\alpha}^{\mathrm{L}}, \mathrm{C}_{\alpha}^{\mathrm{U}}\right)$ is a $\alpha$-level cut of fuzzy number $\tilde{\mathrm{C}}$.

The Yager's ranking index $\mathrm{Y}(\tilde{\mathrm{C}})$ presents the representative value of the fuzzy number $\tilde{\mathrm{C}}$.

If $\tilde{\mathrm{X}}=\mathrm{a} \tilde{\mathrm{W}}+\mathrm{b} \tilde{\mathrm{Z}}$ and $\tilde{\mathrm{P}}=\mathrm{g} \tilde{\mathrm{Q}}-\mathrm{h} \tilde{\mathrm{R}}$ where

$\tilde{\mathrm{X}}, \tilde{\mathrm{W}}, \tilde{\mathrm{Z}}, \tilde{\mathrm{P}}, \tilde{\mathrm{Q}}$ and $\tilde{\mathrm{R}}$ fuzzy numbers and $\mathrm{a}, \mathrm{b}, \mathrm{g}, \mathrm{h}$ are constants.

Then we have,

$\mathrm{Y}(\tilde{\mathrm{X}})=\mathrm{aY}(\tilde{\mathrm{W}})+\mathrm{bY}(\tilde{\mathrm{Z}})$ and

$\mathrm{Y}(\tilde{\mathrm{P}})=\mathrm{gY}(\tilde{\mathrm{Q}})-\mathrm{hY}(\tilde{\mathrm{R}})$

Based on the properties the fuzzy replacement problem can be transformed in to crisp replacement problem.

If $\mathrm{Y}(\tilde{\mathrm{U}}) \leq \mathrm{Y}(\tilde{\mathrm{V}})$, then, using Yager's ranking method, we have $\tilde{U} \leq \tilde{\mathrm{V}}$ i.e. $\min \{\tilde{\mathrm{U}}, \tilde{\mathrm{V}}\}=\tilde{\mathrm{U}}$. Using linearity and additive properties of Yager's ranking method in (1) we get,

$$
\begin{aligned}
& \mathrm{Y}(\tilde{\mathrm{A}}(\mathrm{n}))=\mathrm{Y}\left(\frac{\tilde{\mathrm{C}}-\tilde{\mathrm{S}}}{\mathrm{n}}\right)+\frac{1}{\mathrm{n}} \sum_{\mathrm{t}=1}^{\mathrm{n}} \mathrm{Y}\left(\tilde{\mathrm{f}}_{\mathrm{t}}\right) \\
& \mathrm{Y}(\tilde{\mathrm{A}}(\mathrm{n}))=\frac{1}{\mathrm{n}} \mathrm{Y}-\tilde{\mathrm{S}}_{-}^{-}+\frac{1}{\mathrm{n}} \sum_{\mathrm{t}=1}^{\mathrm{n}} \mathrm{Y}\left(\tilde{\mathrm{f}}_{\mathrm{t}}\right) \\
& \mathrm{Y}(\tilde{\mathrm{A}}(\mathrm{n}))=\frac{1}{\mathrm{n}}\left[\{\mathrm{Y}(\tilde{\mathrm{C}})-\mathrm{Y}(\tilde{\mathrm{S}})\}+\sum_{\mathrm{t}=1}^{\mathrm{n}} \mathrm{Y}\left(\tilde{\mathrm{f}}_{\mathrm{t}}\right)\right]
\end{aligned}
$$

Where $\tilde{\mathrm{A}}(\mathrm{n})$ is the fuzzy average cost and $\tilde{\mathrm{f}}_{\mathrm{t}}$ is the fuzzy maintenance cost. Since $\mathrm{Y}(\tilde{\mathrm{A}}(\mathrm{n})), \mathrm{Y}(\tilde{\mathrm{C}}), \mathrm{Y}(\tilde{\mathrm{S}}), \mathrm{Y}\left(\tilde{\mathrm{f}}_{\mathrm{t}}\right)$ gives a crisp value. So it can be solved by any conventional method.

\section{EXAMPLES}

4.1 Example. A construction company launched a certain type of loader whose fuzzy cost $(\tilde{\mathrm{C}})$ in rupees is $(61000,61300$, $61700,62000)$ and the scrap value $(\tilde{S})$ is $(4200,4250,4300$, 4350). After survey, it has been noticed by company officials that the running cost (maintenance cost (M.C)) in rupees are found from experience (see Table 1). 
Table 1. Yearly maintenance fuzzy cost.

\begin{tabular}{|c|l|}
\hline $\begin{array}{c}\text { Year(n) } \\
\downarrow\end{array}$ & $\begin{array}{l}\text { Maintenance fuzzy cost }\left(\tilde{\mathrm{f}}_{\mathrm{t}}\right) \text { of } \\
\text { loader. } \\
\rightarrow\end{array}$ \\
\hline 1 & $\tilde{\mathrm{f}}_{1}=[1200,1350,1400,1450]$ \\
\hline 2 & $\tilde{\mathrm{f}}_{2}=[2500,2600,2750,2900]$ \\
\hline 3 & $\tilde{\mathrm{f}}_{3}=[3500,3700,3850,4000]$ \\
\hline 4 & $\tilde{\mathrm{f}}_{4}=[4500,4650,4800,5000]$ \\
\hline 5 & $\tilde{\mathrm{f}}_{5}=[6000,6500,6700,6800]$ \\
\hline 6 & $\tilde{\mathrm{f}}_{6}=[8000,8200,8450,8800]$ \\
\hline 7 & $\tilde{\mathrm{f}}_{7}=[10500,11000,12500,14000]$ \\
\hline 8 & $\tilde{\mathrm{f}}_{8}=[16000,17000,18500,20000]$ \\
\hline
\end{tabular}

When would the company officials recommend replacing the loader with a new one? (Take $1000=1$ unit).

Solution :-( 1) To solve this problem, we take RS $1000=1$ unit. First we find out the Yager's ranking index of all fuzzy cost i.e. maintenance cost $\left(\tilde{\mathrm{f}}_{\mathrm{t}}\right)$, capital cost $(\tilde{\mathrm{C}})$, and scrap value $(\tilde{\mathrm{S}})$. So we get the following membership function and their corresponding indices.

$\tilde{\mathrm{f}}_{1}=(1.200,1.350,1.400,1.450)$.

Therefore, we have

$$
\mu_{\mathrm{f}_{\mathrm{t}}}=\left\{\begin{array}{cc}
0, & \mathrm{x} \leq 1.2, \\
\frac{\mathrm{x}-1.2}{1.35-1.2} & , 1.2 \leq \mathrm{x} \leq 1.35 \\
=1, & 1.35 \leq \mathrm{x} \leq 1.4 \\
\frac{1.45-\mathrm{x}}{0.05} & , 1.4 \leq \mathrm{x} \leq 1.45 \\
0, & \mathrm{x} \geq 0
\end{array}\right.
$$

Therefore, $\alpha$-cut of the fuzzy number

$(1.20,1.35,1.40,1.45)$ is

$\left(\mathrm{f}_{1_{\alpha}}^{\mathrm{L}}, \mathrm{f}_{1_{\alpha}}^{\mathrm{U}}\right)=(0.15 \alpha+1.2,1.45-0.05 \alpha)$
Therefore, $\mathrm{Y}\left(\tilde{\mathrm{f}}_{1}\right)=\mathrm{Y}(1.20,1.35,1.40,1.45)=\int_{0}^{1} 0.5\left(\mathrm{f}_{1_{\alpha}}^{\mathrm{L}}+\mathrm{f}_{1_{\alpha}}^{\mathrm{U}}\right) \mathrm{d} \alpha$

$=\int_{0}^{1} 0.5(0.15 \alpha+1.2+1.45-0.05 \alpha) \mathrm{d} \alpha$

$=\int_{0}^{1} 0.5(2.65+0.10 \alpha) \mathrm{d} \alpha$

$=\int_{0}^{1}(1.325+0.05 \alpha) \mathrm{d} \alpha$

$=1.325+0.025=1.3500$

Similarly, we find the value of $\mathrm{Y}\left(\tilde{\mathrm{f}}_{\mathrm{t}}\right)$ for $\mathrm{t}=2,3, \ldots, 8$ (see Table 2).

Table 2. Yager's ranking index of maintenance fuzzy cost.

\begin{tabular}{|l|l|}
\hline $\begin{array}{l}\text { Year(n) } \\
\end{array}$ & $\begin{array}{l}\text { Yager's Ranking index of maintenance } \\
\text { fuzzy cost }\left(\tilde{\mathrm{f}}_{\mathrm{t}}\right) \text { of loader } \rightarrow\end{array}$ \\
\hline 1 & $\mathrm{Y}\left(\tilde{\mathrm{f}}_{1}\right)=1.3500$ \\
\hline 2 & $\mathrm{Y}\left(\tilde{\mathrm{f}}_{2}\right)=2.6125$ \\
\hline 3 & $\mathrm{Y}\left(\tilde{\mathrm{f}}_{3}\right)=3.7625$ \\
\hline 4 & $\mathrm{Y}\left(\tilde{\mathrm{f}}_{4}\right)=4.7375$ \\
\hline 5 & $\mathrm{Y}\left(\tilde{\mathrm{f}}_{5}\right)=6.5000$ \\
\hline 6 & $\mathrm{Y}\left(\tilde{\mathrm{f}}_{6}\right)=8.3625$ \\
\hline 7 & $\mathrm{Y}\left(\tilde{\mathrm{f}}_{7}\right)=12.0000$ \\
\hline
\end{tabular}

We also find out $\mathrm{Y}(\tilde{\mathrm{C}}), \mathrm{Y}(\tilde{\mathrm{S}})$ and their corresponding indices are 61.5000 and 4.2750 respectively. In order to determine the optimal time $\mathrm{n}$, when the machine should be replaced, we calculate an average total cost per year during the life of the equipment. It is shown in the Table 3. 
Table 3. Calculations to determine economic life of item.

\begin{tabular}{|c|c|c|c|c|c|}
\hline $\begin{array}{l}\text { Yea } \\
\mathrm{r} \\
\text { (n) }\end{array}$ & $\begin{array}{l}\text { Runnin } \\
\text { g Cost } \\
\text { f(n) (2) }\end{array}$ & $\begin{array}{l}\text { Cumulat } \\
\text { ive } \\
\text { Running } \\
\text { Cost } \\
\sum_{(3)} Y\left(\tilde{f}_{t}\right)\end{array}$ & $\begin{array}{l}\text { Depre } \\
\text { ciation } \\
\text { cost } \\
\mathrm{Y}(\tilde{\mathrm{C}}) \text { - } \\
\mathrm{Y}(\tilde{\mathrm{S}}) \\
(4)\end{array}$ & $\begin{array}{l}\text { Total } \\
\text { cost } \\
(5)=(3) \\
+(4)\end{array}$ & $\begin{array}{l}\text { Averag } \\
\text { e cost } \\
(6)=\frac{(5)}{n}\end{array}$ \\
\hline 1 & 1.3500 & 1.3500 & 57.225 & 58.5750 & 58.3500 \\
\hline 2 & 2.6125 & 3.9625 & 57.225 & 61.1875 & 30.5937 \\
\hline 3 & 3.7625 & 7.7250 & 57.225 & 64.9500 & 21.6500 \\
\hline 4 & 4.7375 & 12.4625 & 57.225 & 69.6875 & 17.4218 \\
\hline 5 & 6.5000 & 18.9625 & 57.225 & 76.1875 & 15.2375 \\
\hline 6 & 8.3625 & 27.3250 & 57.225 & 84.5500 & 14.0916 \\
\hline 7 & 12.0000 & 39.3250 & 57.225 & 96.5500 & $\underline{13.7928}$ \\
\hline 8 & 17.8750 & 57.2000 & 57.225 & 114.450 & 14.3062 \\
\hline
\end{tabular}

From the Table 3, it is clear that the minimum average annual cost is at the end of $7^{\text {th }}$ year i.e. Rs 13792.8 (taking Rs $1000=1$ unit.). So, we can conclude that the loader should be replaced at the end of 7-th year.

4.2 Example. A truck owner purchased three similar trucks with a fuzzy cost $(\tilde{\mathrm{C}})=(8100000,8150000,8200000)$ in rupees. He finds from his past records that the resale value of trucks is $(\tilde{S})=(202000,204000,206000)$ and maintenance fuzzy costs per hundred hours of these trucks are given in Table 4. (Take 100 hours $=1$ unit and Rs $1000=1$ unit.). Determine at which time it is profitable to replace the Truck with a new one?
Table 4. Maintenance fuzzy cost per 100 hours.

\begin{tabular}{|c|c|}
\hline $\begin{array}{l}\text { Time(n) } \\
\downarrow\end{array}$ & $\begin{array}{l}\text { Maintenance fuzzy } \operatorname{cost}\left(\tilde{\mathrm{f}}_{\mathrm{t}}\right) \text { of trucks. } \\
\rightarrow\end{array}$ \\
\hline 1 & $\tilde{f}_{1}=[130,140,145]$ \\
\hline 2 & $\tilde{f}_{2}=[250,255,260]$ \\
\hline 3 & $\tilde{f}_{3}=[300,315,320]$ \\
\hline 4 & $\tilde{\mathrm{f}}_{4}=[375,385,390]$ \\
\hline 5 & $\tilde{\mathrm{f}}_{5}=[450,465,480]$ \\
\hline 6 & $\tilde{\mathrm{f}}_{6}=[600,615,630]$ \\
\hline 7 & $\tilde{\mathrm{f}}_{7}=[900,925,950]$ \\
\hline 8 & $\tilde{\mathrm{f}}_{8}=[1100,1250,1400]$ \\
\hline 9 & $\tilde{\mathrm{f}}_{9}=[1700,1850,1950]$ \\
\hline 10 & $\tilde{\mathrm{f}}_{10}=[2200,2300,2375]$ \\
\hline
\end{tabular}

Solution: Before Solving this problem, we take 100 hours = 1 unit and Rs $1000=1$ unit. As per previous example, we first transform the FRP to a crisp replacement problem by Yager's Ranking index. So using this we have the Table 5. 
Table 5. Yager's ranking index of maintenance fuzzy cost.

\begin{tabular}{|c|c|}
\hline $\begin{array}{l}\text { Time } \\
\text { (n) } \\
\downarrow\end{array}$ & $\begin{array}{l}\text { Yager's Ranking index of maintenance } \\
\text { fuzzy } \operatorname{cost}\left(\tilde{\mathrm{f}}_{\mathrm{t}}\right) \text { of equipment. } \rightarrow\end{array}$ \\
\hline 1 & $\mathrm{Y}\left(\tilde{\mathrm{f}}_{1}\right)=138.75$ \\
\hline 2 & $\mathrm{Y}\left(\tilde{\mathrm{f}}_{2}\right)=255.00$ \\
\hline 3 & $\mathrm{Y}\left(\tilde{\mathrm{f}}_{3}\right)=312.50$ \\
\hline 4 & $\mathrm{Y}\left(\tilde{\mathrm{f}}_{4}\right)=383.75$ \\
\hline 5 & $\mathrm{Y}\left(\tilde{\mathrm{f}}_{5}\right)=465.00$ \\
\hline 6 & $\mathrm{Y}\left(\tilde{\mathrm{f}}_{6}\right)=615.00$ \\
\hline 7 & $\mathrm{Y}\left(\tilde{\mathrm{f}}_{7}\right)=925.00$ \\
\hline 8 & $\mathrm{Y}\left(\tilde{\mathrm{f}}_{8}\right)=1250.00$ \\
\hline 9 & $\mathrm{Y}\left(\tilde{\mathrm{f}}_{9}\right)=1837.00$ \\
\hline 10 & $\mathrm{Y}\left(\tilde{\mathrm{f}}_{10}\right)=2293.75$ \\
\hline
\end{tabular}

Similarly, we find out $\mathrm{Y}(\tilde{\mathrm{C}}), \mathrm{Y}(\tilde{\mathrm{S}})$ and its corresponding values are 8150.00 and 204.00 respectively.

The average total cost per hundred hours is given in Table 6 .

Table 6. Calculations to determine economic life of item.

\begin{tabular}{|l|l|l|l|l|l|}
\hline Hour & Runnin & Cumula & Depr & Total cost & Averag \\
(n) & $\mathrm{g} \quad$ Cost & tive & eciati & $(5)=(3)+$ & e cost \\
100 & $\mathrm{f}(\mathrm{n})$ & Runnin & on & & $(6)=5 / \mathrm{n}$ \\
$\mathrm{g}$ & Cost & $\mathrm{Y}(\tilde{\mathrm{C}})$ & & \\
$(1)$ & $(2)$ & $(3)$ & cost & & \\
& & & $(4)$ & & $(6)$ \\
& & & & & \\
\hline
\end{tabular}

\begin{tabular}{|c|c|c|c|c|c|}
\hline 1 & 138.75 & 138.75 & 7946 & 8084.75 & 8084.75 \\
\hline 2 & 255.00 & 393.75 & 7946 & 8339.75 & 4169.87 \\
\hline 3 & 312.50 & 706.25 & 7946 & 8652.25 & 2884.08 \\
\hline 4 & 383.75 & 1090.00 & 7946 & 9036.00 & 2259.00 \\
\hline 5 & 465.00 & 1555.00 & 7946 & 9501.00 & 1900.20 \\
\hline 6 & 615.00 & 2170.00 & 7946 & 10116.00 & 1686.00 \\
\hline 7 & 925.00 & 3095.00 & 7946 & 11041.00 & 1577.28 \\
\hline 8 & 1250.00 & 4345.00 & 7946 & 12291.00 & 1536.37 \\
\hline 9 & 1837.00 & 6182.00 & 7946 & 14128.00 & 1569.77 \\
\hline 10 & 2293.75 & 8475.00 & 7946 & 16421.00 & 1642.10 \\
\hline
\end{tabular}

From Table 6, we see that the average cost per hundred hours is minimum, at the end of 800 hours (taking lunit=100 hours) i.e., Rs 1536370 (Taking 1unit=Rs1000). Therefore, we conclude that the truck owner should expect to replacement a truck to a new one at the end of 800 hours.

\section{CONCLUSIONS}

In this paper, the fuzzy replacement problem is considered in the sense that the capital cost, scrap value, maintenance or running cost are all imprecise in nature represented by fuzzy numbers. It is more realistic and closer to our daily life situation. Here, we use Yager's ranking method to deal with this type of FRP. This method shifts the FRP to crisp RP with its corresponding ranking indices. This method is simple and easy to apply for solving practical FRP. Two numerical examples have been provided to show the simplicity and effectiveness of the proposed method. It also shows that proper decision for replacement of FRP can be made easily. We hope that the proposed method may be used for future study in FRP when the value of money dependent on time.

\section{ACKNOWLEDGMENTS}

The authors would like to acknowledge the constructive comments and suggestions of the anonymous experts. 


\section{REFERENCES}

[1] Bellman, R.E., 1955. Equipment replacement policy. SIAM Journal Applied Mathematics 3,133-136.

[2] Bellman, R.E., and Dreyfus, S.E. 1962. Applied Dynamic Programming. Princeton University Press, Princeton, NJ.

[3] Wagner, H.M., 1975. Principles of Operations Research. Prentice-Hall.

[4] Oak ford, R.V., Lohmann, J.R., and Salazar, A.1984. A dynamic replacement economy decision model. IIE Transactions 16, 65-72.

[5] Alchian, A.A.1952. Economic replacement policy. Technical Report Publication R-224. The RAND Corporation, Santa Monica, CA.

[6] Dreyfus, S.E., and Law, A.M. 1977. The Art and Theory of Dynamic Programming. Academic Press, New York.

[7] Lohmann, J.R. 1986. A stochastic replacement economic decision model. IEEE Transactions 18, 182-194.

[8] Dong .W, and Shah, H.C. 1987. Vertex method for computing functions of fuzzy variables. Fuzzy Sets and Systems 14, 65-78.

[9] Chiu C.Y., and Park, C.S. 1994. Fuzzy cash flow analysis using present worth criterion. The Engineering Economist 39(2), 113-138.

[10] Hearnes, W.E. 1995. Modeling with possibilistic uncertainty in the single asset replacement problem. In Proceedings of the International Joint Conference on Information Science, Fourth Annual Conference on Fuzzy
Theory \& Technology, pages 552-555. Wrightsville Beach, NC. (September 28 - October 1. 1995), 552-555.

[11] Yager, R.R., 1981. A procedure for ordering fuzzy subsets of the unit interval. Information Sciences 24, 143161.

[12] Zadeh, L.A. 1975.The concept of a linguistic variable and its application to approximate reasoning i, ii, iii. Information Sciences, 8-9:8:199-251; 8:301-357; 9:43-80.

[13] Dubois, D., and Prade, H.1978. Operations on fuzzy numbers. International Journal of Systems Science 9, 612-626.

[14] Zimmerman, H.J. 1991. Fuzzy Set Theory and Its Applications. Kluwer Academic Press, Boston, MA, second edition.

[15] Dubois, D., and Prade, H. 1987. Fuzzy numbers: An overview. In J.C. Bezdek, editor, Analysis of Fuzzy Information 1, 3-39. CRC Press, Boca Raton, FL.

[16] Kaufmann, A., and Gupta, M. M.1988. Fuzzy Mathematical Models in Engineering and Management Science. Elsevier Science Publishers, B.V.

[17] Klir, G.J., and Yuan, B.1995. Fuzzy Sets and Fuzzy Logic: Theory and Applications. Prentice Hall PTR, Upper River Saddle, NJ.

[18] Zadeh, L.A., 1965. Fuzzy sets, Information and control 8 338-353. 